\title{
Effects of Geometry and Hydraulic Characteristics of Shallow Reservoirs on Sediment Entrapment
}

\author{
Hamidreza Zahabi ${ }^{1}$, Mohammadamin Torabi ${ }^{2}{ }^{\circ}$, Ebrahim Alamatian ${ }^{3}$, Mehdi Bahiraei ${ }^{4}$ \\ and Marjan Goodarzi ${ }^{\text {,*(D) }}$ \\ 1 Department of Civil Engineering, Institute Superior Tecnico, 1049-001 Lisbon, Portugal; \\ hamidreza.zahabi@tecnico.ulisboa.pt \\ 2 Department of Civil and Environmental Engineering, Idaho State University, Pocatello, ID 83209, USA; \\ toramoha@isu.edu \\ 3 Department of Civil Engineering, Khavaran Institute of Higher Education, Mashhad, Iran; \\ E.alamatian@profs.khi.ac.ir \\ 4 Department of Mechanical Engineering, Kermanshah University of Technology, Kermanshah, Iran; \\ m.bahiraei@kut.ac.ir \\ 5 Sustainable Management of Natural Resources and Environment Research Group, Faculty of Environment \\ and Labour Safety, Ton Duc Thang University, Ho Chi Minh City, Vietnam \\ * Correspondence: marjan.goodarzi@tdtu.edu.vn; Tel.: +1-502-432-0339
}

Received: 29 October 2018; Accepted: 19 November 2018; Published: 26 November 2018

\begin{abstract}
Sediment and deposition are among the main problems in dam engineering and other related fields. Because of the numerous advantages of numerical modeling, effects of different geometries of reservoirs on the flow pattern and deposition of sediments are investigated using the finite volume based Flow-3D software package. In this study, three rectangular reservoirs with different dimensional ratios are simulated using the large eddy simulation (LES) turbulence model. To validate the numerical modeling, existing experimental data is used. Results indicate that Flow-3D can accurately simulate flow and sediment deposition in the reservoirs, and the numerical data are in reasonable agreement with the experimental results. Numerical efforts showed that the amount of deposition in reservoirs is significantly dependent on the geometry. Among the modeled reservoirs, the $6 \times 4 \mathrm{~m}$ one has the best performance. Moreover, it can be said that changing the position of the flow's inlet and outlet of the reservoir does not have a considerable effect on increasing its efficiency.
\end{abstract}

Keywords: shallow reservoirs; LES turbulence model; sediment; Flow-3D

\section{Introduction}

One of the critical issues in the multi-purpose reservoir is sedimentation and deposition management. Shallow reservoirs [1,2] are an illustration of these, which are used to manage stormwater. Scientists have always been struggling with the challenge of predicting the amount of deposition and the sludge layers in reservoirs. Because storm flow contains a large volume of particles, e.g., sand, gravel, and mud, along with fine and coarse stones, as well as driftwood [3,4]. Shallow reservoirs have been widely used as ponds with the capability of restoring particles $[5,6]$. They can also be used as storage [7-10], sedimentation tanks [11,12], and service reservoirs in water supply systems [13]. To legitimately predict the amount of deposition and sedimentation pattern, the hydrodynamics of the reservoir should be identified correctly. The flow pattern, velocity of the main jet, eddies, and the recirculation zones need to be studied to achieve this [14-16]. One of the fundamental parameters in this regard is geometry, which includes the general shape of the reservoir and the position of the inlet and outlet. Several scientists have investigated this parameter so far. In 2001, Wu used 
CCHE2D (The University of Mississippi, Oxford, MS, USA) to numerically model flow and sediment deposition in an open channel $[17,18]$. Researchers like Kantoush (2007) and Dewals (2008) worked on the effect of the width of a shallow rectangular reservoir to observe the sedimentation behavior $[19,20]$. They concluded symmetric geometry does not obligate the flow pattern to be symmetric. Depositions can become asymmetric by reducing the width of the reservoir. In 2009, Johnson et al. also investigated the effects of sediment particle size and the geometry of a basin [21]. Dufresne, in 2011, defined a shape parameter for the shallow rectangular reservoir and experimentally indicated that reservoirs with a shape parameter greater than 6.8 are prone to sediment deposition [15].

The other parameter that researchers investigated was the non-symmetric configuration of the inlet and outlet. Horacio, in 2009 [22], worked on the position of the inlet and outlet. He indicated that the location of the hydraulic jump plays the primary role in the final bed deposition. Camnasio et al. [23], in 2010, and other researchers [24,25] studied the locations of the inlet and outlet. Camnasio concluded that deposits could modify the direction of the main jet and flow pattern. Moreover, a theoretical approach based on thermodynamic optimality was presented recently by Westhoff et al. (2018) that proves this fact [26].

Predicting deposition and erosion as a function of the geometry for different structures, like reservoirs and breakwaters [27], as well as of the hydraulic conditions and sediment characteristics, is still a great challenge. The purpose of the current study is to investigate the effects of the dimensions and geometry of shallow reservoirs on flow hydraulics and sediment distribution within them. To do this, the commercial software computational fluid dynamic (CFD) package (Flow-3D, Flow Science, Santa Fe, NM, USA) is used [28].

\section{Governing Equations}

Numerical modeling in recent years has obtained much attention. The computational fluid dynamic (CFD) package used in this study is based on solving the Navier-Stokes equation. The governing equations on incompressible, Newtonian, turbulent flow consist of equations for continuity, momentum, and convection written in 3-D. In order to model the turbulence, the large eddy simulation (LES) method with the Smagorinsky subgrid-scale (SGS) is implemented. The LES method is based on solving large eddies and modeling small eddies, which are done by imposing filters on the governing equations. The Smagorinsky method assumes that the energy and dissipation of the small scale eddies are in equilibrium [29-31]. The filtered forms of the governing equations for an incompressible fluid are given in Equations (1)-(5) [32]:

1. Continuity:

$$
\frac{D \rho}{D t}+\rho \frac{\partial u_{i}}{\partial x_{i}}=0
$$

2. Momentum:

$$
\frac{\partial \overline{u_{i}}}{\partial t}+\frac{\partial \overline{u_{i} u_{j}}}{\partial x_{j}}=-\frac{1}{\rho} \frac{\partial \bar{p}}{\partial x_{i}}+\frac{\partial}{\partial x_{j}}\left(v \frac{\partial \overline{u_{j}}}{\partial x_{j}}\right)
$$

3. Diffusion:

$$
\frac{\partial \bar{\phi}}{\partial t}+\frac{\partial \overline{u_{j} \phi}}{\partial x_{j}}=\frac{\partial}{\partial x_{j}}\left(D \frac{\partial \bar{\phi}}{\partial x_{j}}\right)
$$

4. Smagorinsky-Lilly model:

$$
\begin{gathered}
v_{t}=\left(C_{s} \Delta_{g}\right)^{2} \sqrt{2 \bar{S}_{i j} \bar{S}_{i j}}=\left(C_{s} \Delta_{g}\right)^{2}|S| \\
\bar{S}_{i j}=\frac{1}{2}\left(\frac{\partial \bar{u}_{j}}{\partial x_{i}}+\frac{\partial \bar{u}_{i}}{\partial x_{j}}\right)
\end{gathered}
$$

The other essential equation implemented in this simulation is the sediment scour model. Sediment transport calculations include three parts: entrainment and deposition, suspended load 
transport, and bedload transport. In the entrainment process, turbulent eddies take the grains from the packed bed and transport them into suspension. Afterward, the suspended sediments are transported by the flow at a particular height above bed, with deposition being the final step after the sediments have settled out of suspension. Equation (5) indicates suspended load transport:

5. Suspended load transport

$$
\frac{\partial C_{s, n}}{\partial t}+\nabla \cdot\left(C_{s, n} u_{s, n}\right)=\nabla \cdot \nabla\left(D C_{s, n}\right)
$$

where $C_{s, n}$ is the suspended sediment mass concentration, $D$ is diffusivity, and $u_{s, n}$ is the sediment velocity.

\section{Numerical Modeling}

In this research, the RANS-VOF model has been used to simulate the effects of the dimensions and geometry of shallow reservoirs on flow hydraulics and sediment distribution. Three different geometries and sizes, as can be seen in Table 1, were tested. The Meyer-Peter and Müller method were used for sediment transport [33]. The initial sediment concentration was considered to be $3 \mathrm{~kg} / \mathrm{m}^{3}$ in the inlet. The height of the reservoir walls and sediment loading of the flow at the inlet were considered identical at $0.3 \mathrm{~m} \mathrm{[34],} \mathrm{with} \mathrm{an} \mathrm{initial} \mathrm{water} \mathrm{level} \mathrm{of} 0.2 \mathrm{~m}$. The six boundary conditions were defined as follows: sidewalls $y$-symmetry, specified top pressure with a fluid fraction of zero, $X_{\min }$ inlet boundary condition considered as specified pressure with stagnation, constant fluid elevation of $0.2 \mathrm{~m}$, and $X_{\text {max }}$ considered as an outflow. The sand considered as sediment in this simulation has the characteristics shown in Table 2.

Table 1. The geometry of the reservoirs.

\begin{tabular}{cccc}
\hline Geometry & Width $(B)(\mathbf{m})$ & Length $(\mathrm{L})(\mathbf{m})$ & Ratio \\
\hline G1 & 2 & 6 & $1 / 3$ \\
G2 & 4 & 3 & $4 / 3$ \\
G3 & 4 & 6 & $2 / 3$ \\
\hline
\end{tabular}

Table 2. Properties of the sediment.

\begin{tabular}{ccc}
\hline Property & Density $\left(\mathbf{k g} / \mathbf{m}^{3}\right)$ & Diameter $(\mu \mathrm{m})$ \\
\hline Value & 1500 & 50 \\
\hline
\end{tabular}

Grid convergence was done for each configuration by comparing velocity along the $X$-axis. Four different mesh sizes were considered, with total cells numbering $2.0 \times 10^{4}, 1.0 \times 10^{5}, 1.5 \times 10^{5}$, and $2.0 \times 10^{5}$. Figure 1 shows the resultant convergences for each mesh size. Cases 2 to 4 have very similar results (less than $3 \%$ difference), and in order to make the simulations time-efficient, case 2 was selected as the objective mesh size. 


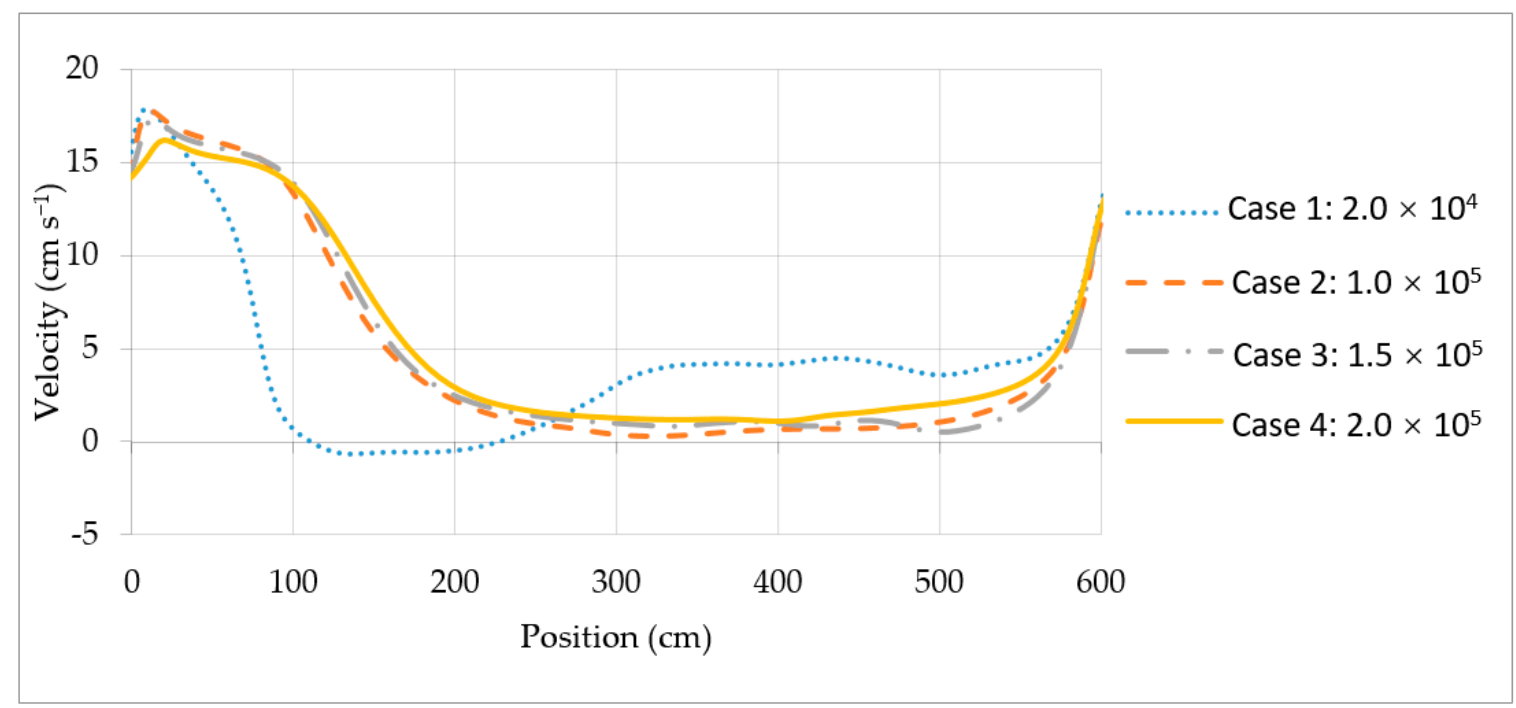

Figure 1. Grid convergence for different cell sizes.

Figure 2 provides an overview of the reservoir and the positions of the inlet and outlet. The inflow has two phases of fluid and sediment.

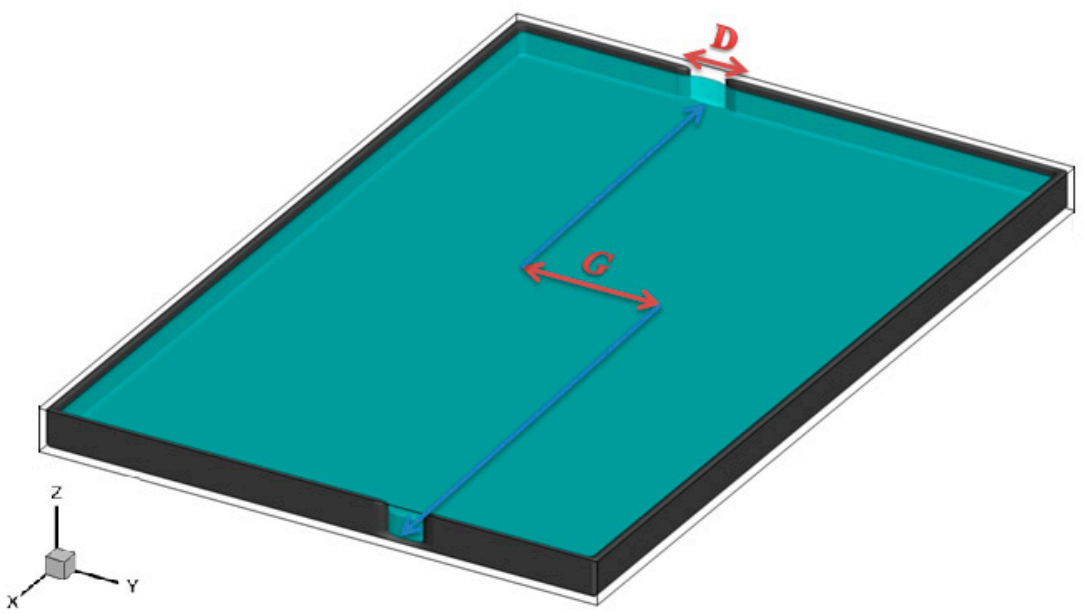

Figure 2. The positions of the inlet and outlet in the reservoir.

In order to verify the model, the G1 reservoir, with the dimensions of $6 \times 2 \mathrm{~m}$, was selected to compare the amount of deposited sediment in the numerically and experimentally modeled reservoir. Figure 3 shows the profile of the accumulated sediment on the reservoir's bed after $4.5 \mathrm{~h}$ at the cross-section of $\mathrm{y}=1 \mathrm{~m}$. 


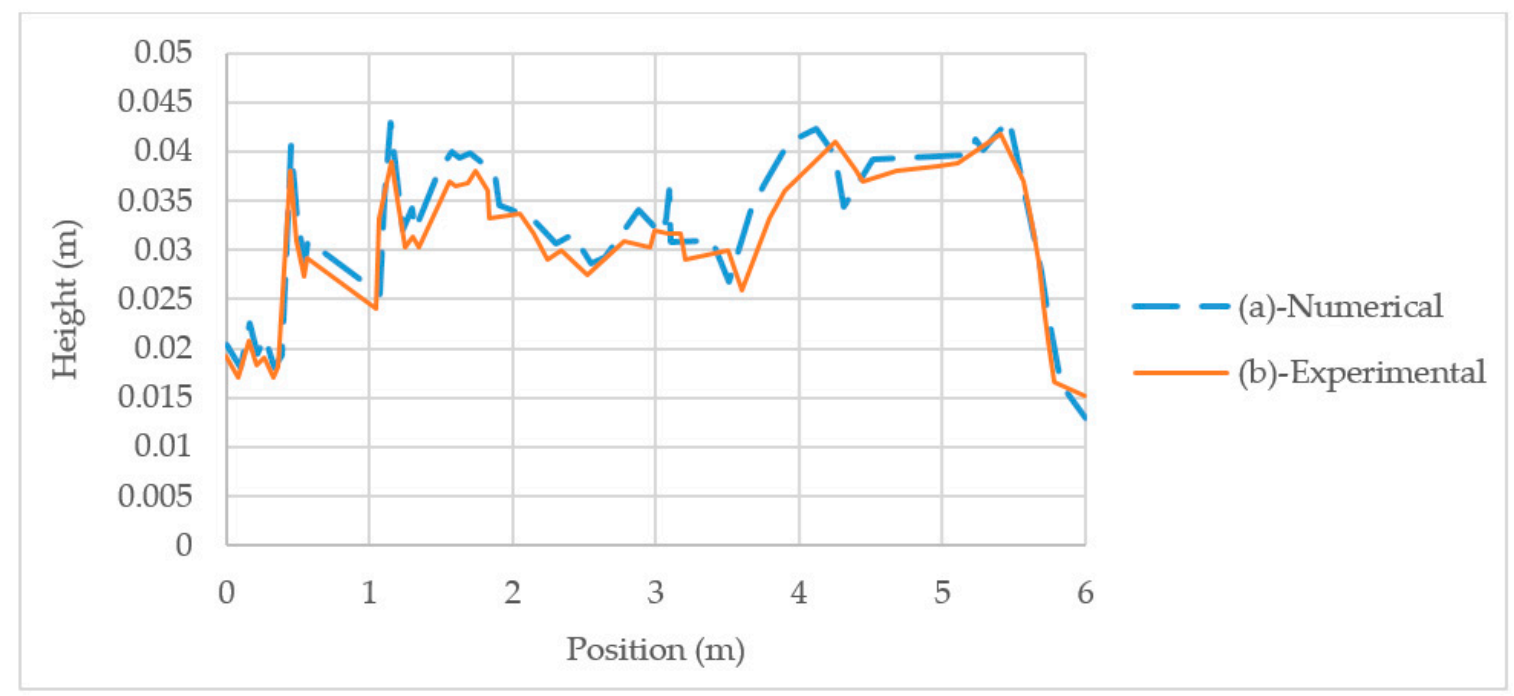

Figure 3. Profile of deposition in the reservoir for (a) numerical and (b) experimental data [35].

In Figure 3, the horizontal axis shows the length of the reservoir, and the vertical axis shows the amount of deposited sediment in the lateral cross-section at $1 \mathrm{~m}$. It can be claimed that the numerical modeling has a reasonable accuracy (less than $5 \%$ difference with experimental data, on average) and is slightly overestimated, which is reliable in view of the safety factor [36].

\section{Results and Discussion}

In this section, the effects of changing three parameters, including the eccentricity (G/D), dimensional ratio, and the flow rate, were studied. The method considered for designing the tests in this research was a full-factor method. Based on this method, for each geometry and each flow rate, different G/D were tried, and 42 simulations were performed in all to see their effects on deposition (Table 3).

Table 3. Test setups.

\begin{tabular}{ccc}
\hline Geometry & G/D & Q (L/s) \\
\hline G1 & $0,2,4,8$ & $7,35,63$ \\
G2 & $0,2,4,8,16$ & $7,35,63$ \\
G3 & $0,2,4,8,16$ & $7,35,63$ \\
\hline
\end{tabular}

\subsection{Dimensional Ratio}

One of the important parameters in capturing sediment is the geometry of the reservoir. In this section, the effects of length and width in different rectangular geometries (G1, G2, G3), along with a flow rate of $7 \mathrm{~L}$ per second and $\mathrm{G} / \mathrm{D}=2$, were investigated. For brevity, the reservoirs are named symbolically. For instance, G172 indicates the first reservoir G1 with the dimensions of $6 \times 2 \mathrm{~m}$, a flow rate of $7(\mathrm{~L} / \mathrm{s})$, and the ratio of $\mathrm{G} / \mathrm{D}=2$.

Figure 4 shows the amount of sediment deposition with regards to time for the three reservoirs. It can be seen that in all the reservoirs, the amount of deposition increases with time. Reservoir G372 has a higher efficiency than the other two by trapping $72.51 \%$ of the inflow sediment loading in comparison to $71.1 \%$ for the G172 and $62 \%$ for the G272 reservoir. Comparing reservoirs G2 and G3, and also G1 and G3, shows the effects of length and width in the amount of entrapment, respectively. Results indicate that increasing the length by $100 \%$ enhances the efficiency by $10 \%$, but increasing the width by $100 \%$ can only enhance the efficiency by $1.4 \%$. It shows that stretched reservoirs have a better capability for trapping sediment. 
Since reservoir G3 has more potential to capture the sediment, the effects of eccentricity (G/D) in this specific geometry (G3) are investigated in the following section.

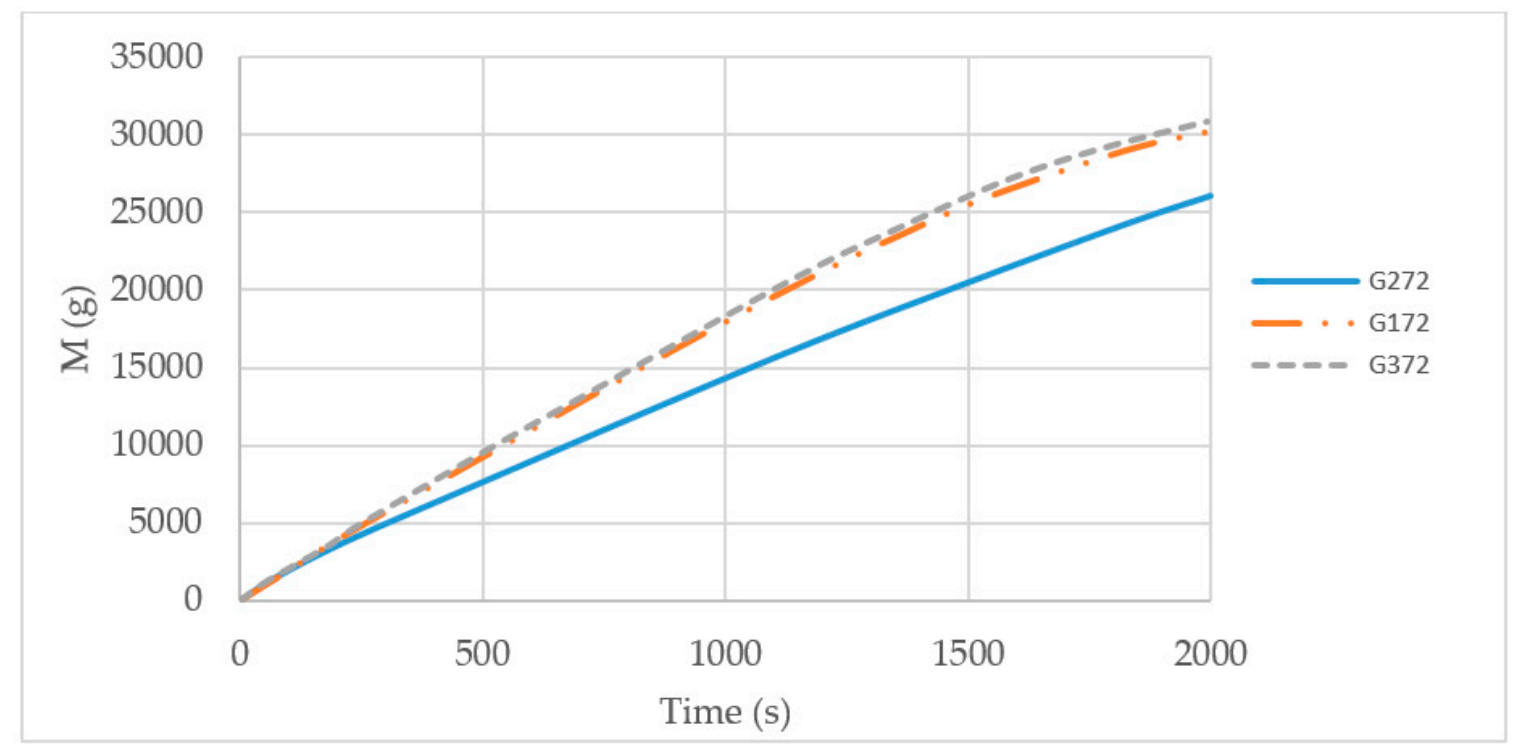

Figure 4. Amount of deposition in the three reservoirs over $2000 \mathrm{~s}$.

\subsection{Effect of the $G / D$ Ratio}

The G3 reservoir has better capabilities than the others, regarding controlling the sediment load. In this section, the effect of changing the G/D ratio on sediment deposition capacity of the G3 reservoir is investigated. The modeling in this section has been done for five G/D ratios with the same flow rate $(7.0 \mathrm{~L} / \mathrm{s})$. In Figures 5-8, the amount and pattern of sediment deposition, and also streamlines in the G374 and G3716 reservoirs, are indicated. The formation of flow vortices and deposition in the reservoirs are apparent in the illustrations. It can be observed that the volume fraction of the sediment loading in the fluid is small at the inlet, and it increases as it gets further from it, which can be attributed to the higher flow velocity at the inlet.

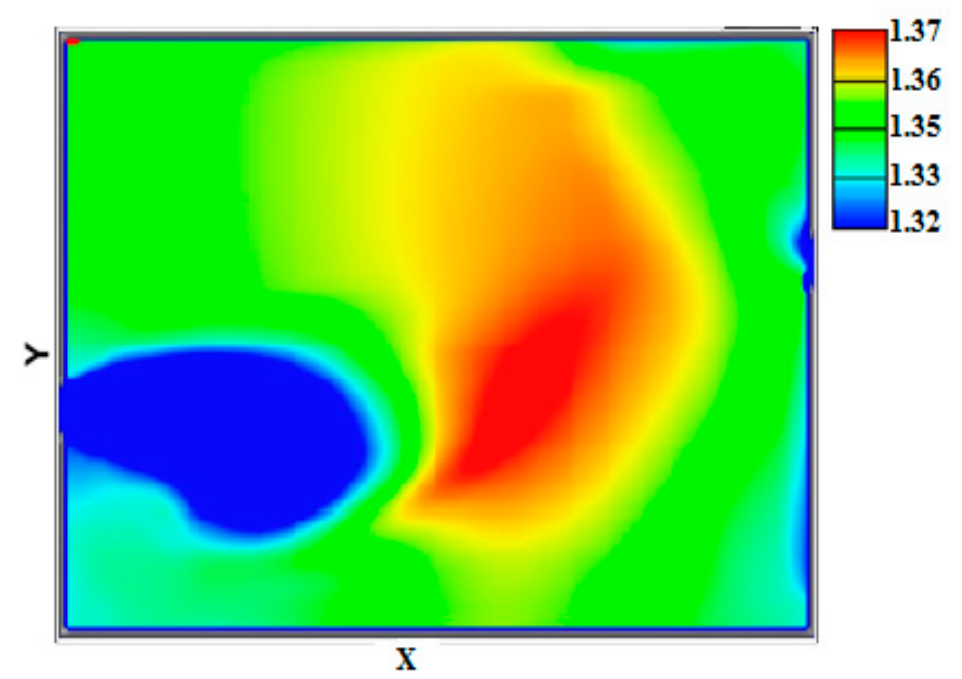

Figure 5. The pattern of sediment deposition in G374 reservoir. 


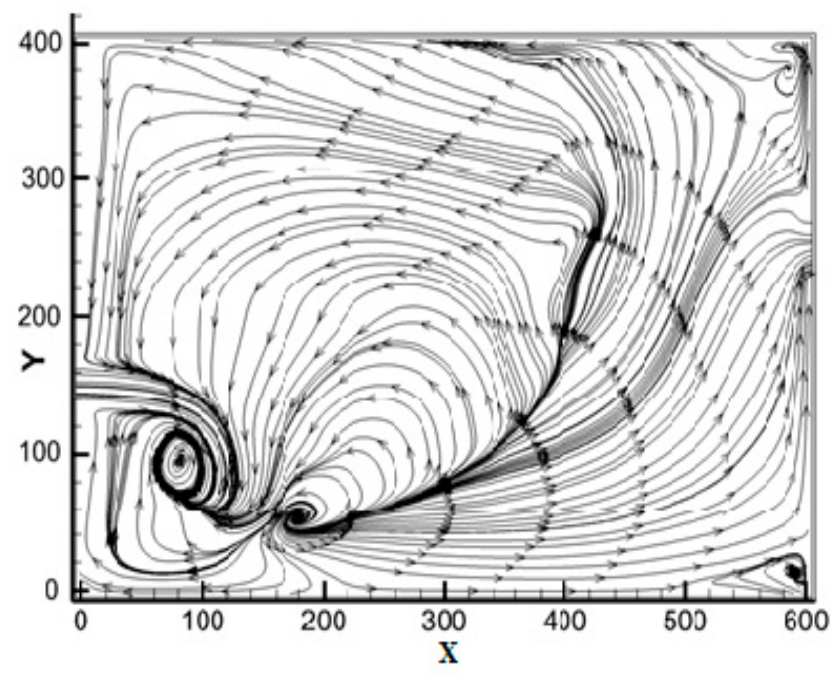

Figure 6. Stream Lines $15.5 \mathrm{~cm}$ from the bed, G374 reservoir.

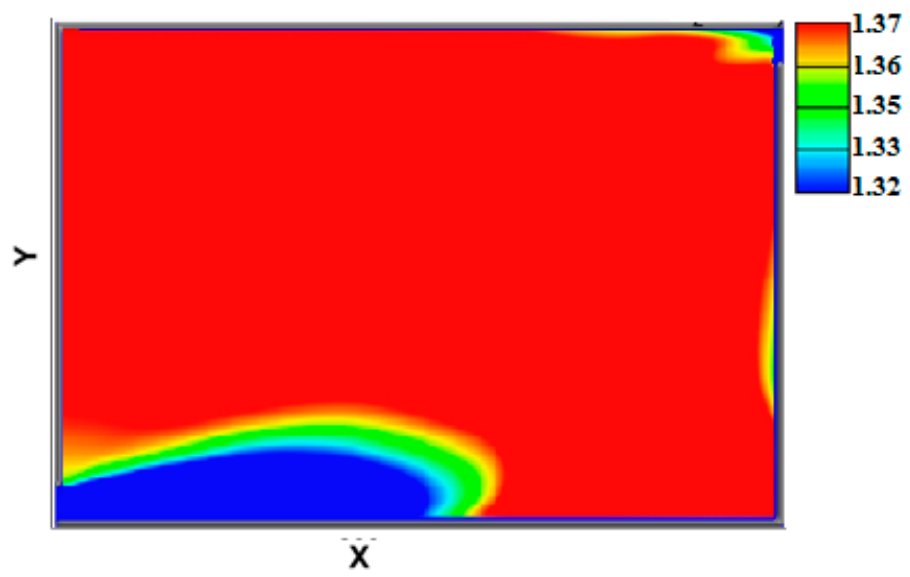

Figure 7. The pattern of sediment deposition in the G3716 reservoir.

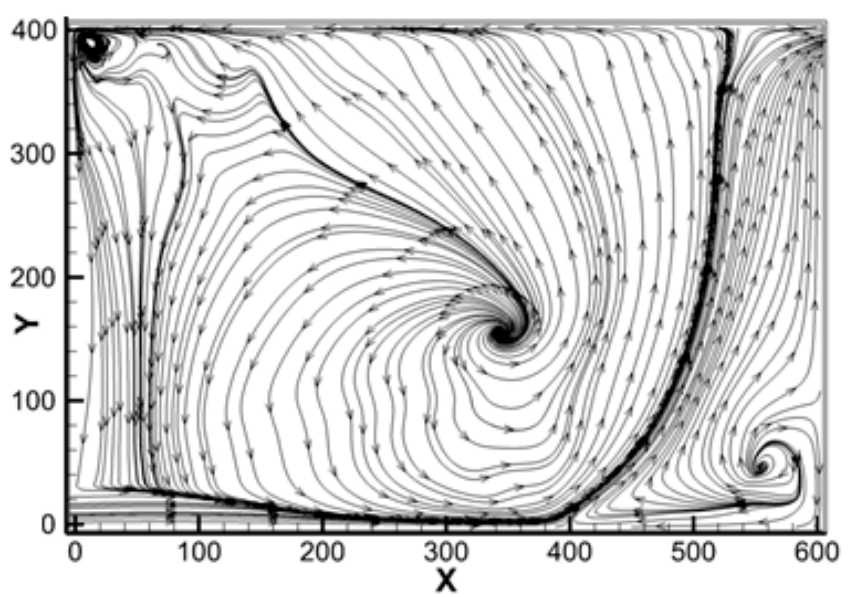

Figure 8. Stream Lines $15.5 \mathrm{~cm}$ from the bed, G3716 reservoir.

The amounts of sediment deposition in reservoirs with different G/D ratios are presented in Table 4. These data indicate the capabilities of the considered reservoirs with different G/D in controlling sediment loading. It can be mentioned that the reservoir with the ratio of $\mathrm{G} / \mathrm{D}=16$ has $73.94 \%$ efficiency in trapping the sediment load, while the reservoir with the ratio of $G / D=0$ has $72.34 \%$. 
Table 4. The amount of sediment entrapped for different G/D.

\begin{tabular}{cccccc}
\hline Reservoir & G370 & G372 & G374 & G378 & G3716 \\
\hline Amount of Sediment & $72.34 \%$ & $72.51 \%$ & $73.31 \%$ & $73.54 \%$ & $73.94 \%$ \\
\hline
\end{tabular}

\subsection{Changing the Flow Rate of the Inflow}

In this section, the effects of changing the flow rate of the inflow on sediment deposition patterns is investigated. For this purpose, the effects of three flow rates $(7,35$, and $63 \mathrm{~L} / \mathrm{s})$ are studied in the G3 reservoir. Since the amount of the inflow sediment load is the constant value of $3 \mathrm{~g}$ per liter, it is evident that by increasing the flow rate of the inflow, more sediment enters the reservoir. Figure 9 is derived from the simulation and represents the flow's kinetic energy and drag coefficient for a specific point in the reservoir (G36316).

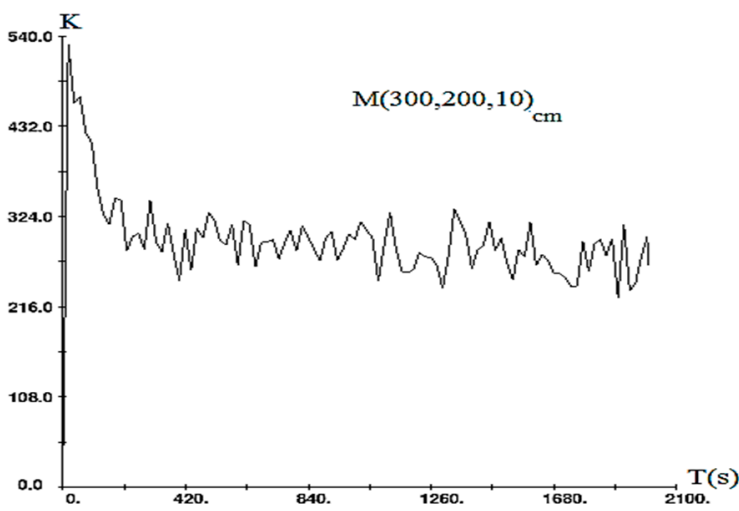

(a)

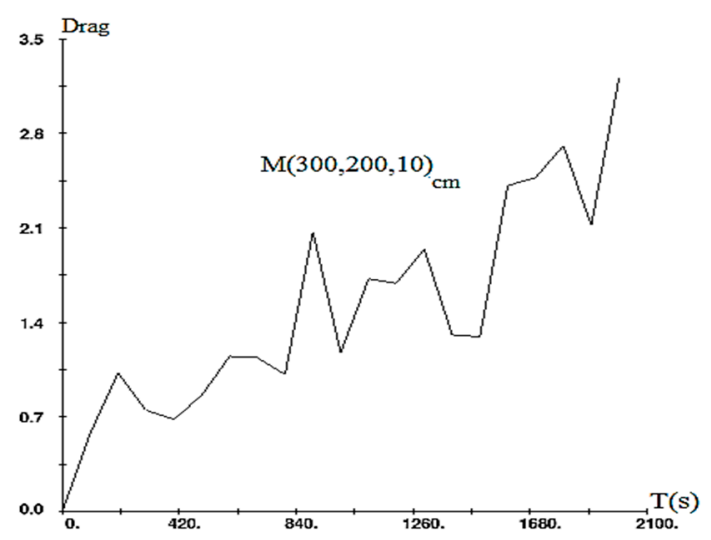

(b)

Figure 9. Variations in point M's (a) kinetic energy and (b) drag coefficient in the G36316 reservoir.

The horizontal axis in Figure 9 indicates time, and the vertical axis is the kinetic energy and drag coefficient for (a) and (b), respectively. In Figure 9a, because of the accumulation of the sediment as the time passes, the kinetic energy at point $M$ decreases, but in Figure 9b, the drag coefficient gradually increases. The reason for this decrease in kinetic energy as time passes while the drag coefficient is increasing is attributed to the sediment volume fraction in the flow. As the volume fraction of the sediment load increases with time, the viscosity of the fluid increases. This will result in a reduction in the kinetic energy and an increase in the drag coefficient. Moreover, the reason for the fluctuations in the kinetic energy and drag coefficient is the change in the amount of sediment in this small period of time. However, since the sediment will accumulate, the kinetic energy will gradually decrease and the drag coefficient will rapidly increase at the point of $\mathrm{M}^{\prime}$. These results are similar for the other two reservoirs. In Figure 10, the final result of the three reservoirs with three different flow rates is illustrated. 


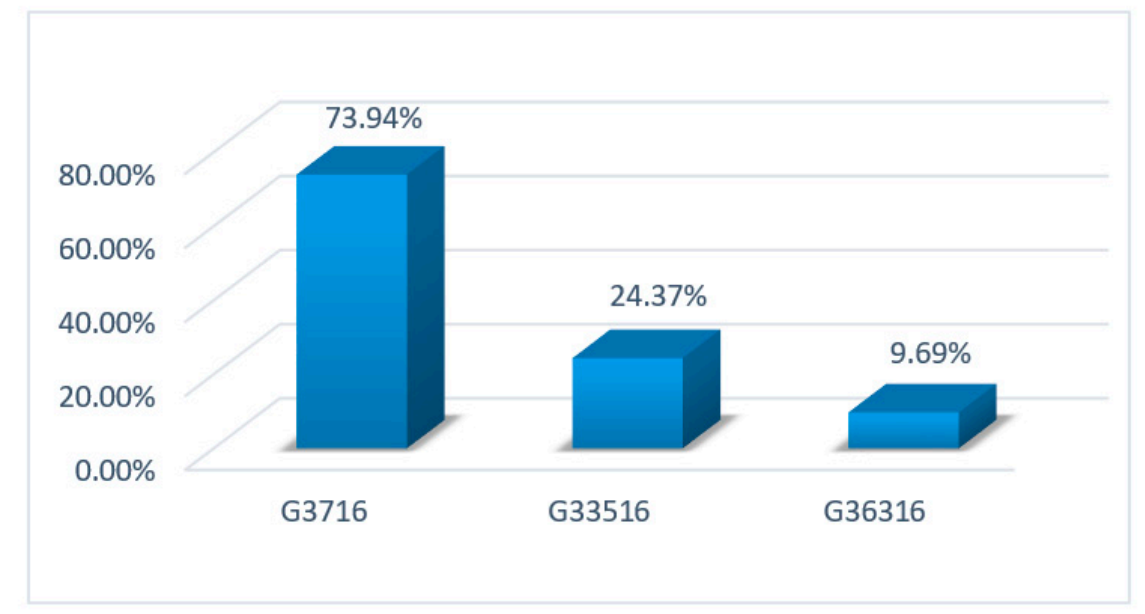

Figure 10. The amount of sediment deposition in the G3 reservoir for different flow rates.

According to these percentages, it can be concluded that by increasing the flow rate, or in other words, by increasing the inflow Froude number, the efficiency of sediment-entrapment reservoirs will be reduced substantially.

\subsection{Sensitivity of Variables}

The sensitivity of the parameters is another important issue which can indirectly increase the efficiency in industry. It indicates how the system can become more efficient by minimizing the effort and which variables are more sensitive to change. Figure 11 indicates the sensitivities of the parameters factoring into sedimentation. By calculating the margins of error in relation to confidence interval, Equation (6), it can be predicted which parameter has more effect on efficiency. The second part of Equation (6) shows the margins of error, these results being indicated in Table 5.

$$
\bar{x} \pm 1.96 \frac{\sigma}{\sqrt{n}}
$$

Table 5. Margins of error of parameters.

\begin{tabular}{cc}
\hline Variables & Margin of Error \\
\hline Flow rate & 0.381 \\
Dimensional ratio & 0.064 \\
Eccentricity (G/D) & 0.005 \\
\hline
\end{tabular}

According to the Table 5 and Figure 11, the flow rate has more sensitivity to changes than the other parameters, dimensional ratio and eccentricity $(\mathrm{G} / \mathrm{D})$. This means changing the flow rate can be the most efficient and easiest way to entrap the sediment. The reason for all these behaviors relates to the amount of time that takes for fluid to go from inlet to outlet. The longer the fluid can be kept in the reservoir, the more sediment will be trapped. 


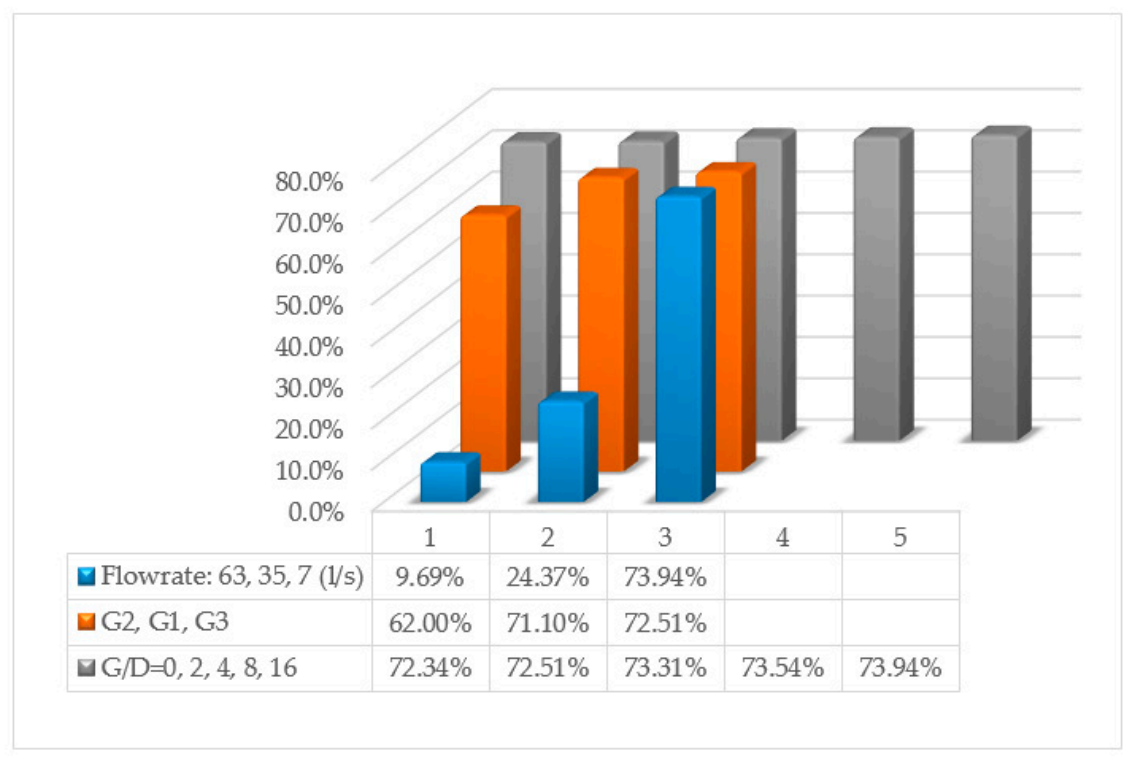

Figure 11. Sensitivity of each parameter to changes.

\section{Conclusions}

Utilizing CFD commercial package Flow-3D, in this study, the effects of geometry, the eccentricity of inlet and outlet (G/D), and the flow rate of the reservoirs on sediment distribution and entrapment were investigated. For this purpose, three reservoirs with different dimensional ratios were simulated. The effects of changing the positions of the inlet and outlet in reservoirs (G/D ratio) on the efficiency of sediment entrapment was investigated. Results showed that by increasing the G/D ratio in the reservoir, the percentage of sediment entrapment slightly increased, and by increasing the flowrate, the amount of sediment entrapment remarkably decreased. Numerical modeling showed that among the simulated reservoirs, the reservoir with dimensions of $6 \times 4 \mathrm{~m}$ and with the ratio of $\mathrm{G} / \mathrm{D}=16 \mathrm{had}$ the best performance. According to the simulation outcomes, it can be concluded that increasing the reservoir length contributes more to sediment entrapment than increasing the width of the reservoir.

Author Contributions: Conceptualization, E.A., M.B., and M.G.; methodology, H.Z. and M.T.; software, H.Z. and M.T.; validation, H.Z. and M.T.; formal analysis, H.Z. and M.T.; investigation, H.Z. and M.T.; resources, H.Z. and M.T.; data curation, H.Z. and M.T.; writing-original draft preparation, M.T. and H.Z.; writing-review and editing, E.A., M.B. and M.G.; visualization, H.Z., M.G. and M.T.; supervision, E.A.; project administration, M.B., M.G. and E.A.; funding acquisition, M.B. and M.G.

Funding: This research received no external funding.

Conflicts of Interest: The authors declare no conflict of interest.

\section{Nomenclature}

\begin{tabular}{ll}
\hline$v$ & Kinematic viscosity $\left(\mathrm{m}^{2} / \mathrm{s}\right)$ \\
$u$ & Velocity $(\mathrm{m} / \mathrm{s})$ \\
$\mathrm{B}$ & Width $(\mathrm{m})$ \\
$\mathrm{L}$ & Length $(\mathrm{m})$ \\
$\bar{u}$ & Filtered velocity $(\mathrm{m} / \mathrm{s})$ \\
$\bar{p}$ & Filtered pressure $(\mathrm{Pa})$ \\
$D$ & Diffusion coefficient $\left(\mathrm{m}^{2} / \mathrm{s}\right)$ \\
$\bar{S}$ & Filtered rate-of-strain tensor \\
$C_{s}$ & Smagorinsky coefficient \\
$\Delta_{g}$ & Grid size $\left(\mathrm{m}^{3}\right)$ \\
$C_{s, n}$ & Suspended sediment mass concentration $\left(\mathrm{kg} / \mathrm{m}^{3}\right)$ \\
\hline
\end{tabular}




\begin{tabular}{ll}
\hline$u_{s, n}$ & Sediment velocity $(\mathrm{m} / \mathrm{s})$ \\
$\sigma$ & Standard deviation \\
$n$ & Number of data \\
$\bar{x}$ & Average of data \\
$\mathrm{G} / \mathrm{D}$ & Eccentricity \\
$\mathrm{Q}$ & Flow rate $(\mathrm{L} / \mathrm{s})$ \\
$\rho$ & Density $\left(\mathrm{kg} / \mathrm{m}^{3}\right)$ \\
$t$ & Time $(\mathrm{s})$ \\
$\bar{\phi}$ & Scalar \\
$i$ & Unit in $x$ direction \\
$j$ & Unit in $y$ direction \\
$x$ & Direction \\
\hline
\end{tabular}

\section{References}

1. Abbasi, A.; Annor, F.O.; van de Giesen, N. Investigation of temperature dynamics in small and shallow reservoirs, case study: Lake Binaba, Upper East Region of Ghana. Water 2016, 8, 84. [CrossRef]

2. Jamalabadi, M.; Ho-Huu, V.; Nguyen, T. Optimal design of circular baffles on sloshing in a rectangular tank horizontally coupled by structure. Water 2018, 10, 1504. [CrossRef]

3. Ebnjalal, R.; Bajestan, S. Theoretical and Practical Principles of Soil Mechanics, 4th ed.; Shahid Chamran University Press: Ahvaz, Iran, 2004.

4. Kuksina, L. Variations of water runoff and suspended sediment yield in the Kamchatsky Krai, Russia. Water 2018, 10, 1451. [CrossRef]

5. Dominic, J.A.; Aris, A.Z.; Sulaiman, W.N.A.; Tahir, W.Z.W.M. Discriminant analysis for the prediction of sand mass distribution in an urban stormwater holding pond using simulated depth average flow velocity data. Environ. Monit. Assess. 2016, 188, 191. [CrossRef] [PubMed]

6. Sebastian, C.; Becouze-Lareure, C.; Kouyi, C.L.; Barraud, S. Event-based quantification of emerging pollutant removal for an open stormwater retention basin-Loads, efficiency and importance of uncertainties. Water Res. 2015, 72, 239-250. [CrossRef] [PubMed]

7. Adamsson, Å.; Stovin, V.; Bergdahl, L. Bed shear stress boundary condition for storage tank sedimentation. J. Environ. Eng. 2003, 129, 651-658. [CrossRef]

8. Michalec, B. Evaluation of an empirical reservoir shape function to define sediment distributions in small reservoirs. Water 2015, 7, 4409-4426. [CrossRef]

9. Tsavdaris, A.; Mitchell, S.; Williams, J.B. Computational fluid dynamics modelling of different detention pond configurations in the interest of sustainable flow regimes and gravity sedimentation potential. Water Environ. J. 2015, 29, 129-139. [CrossRef]

10. Michalec, B. The use of modified Annandale's method in the estimation of the sediment distribution in small reservoirs-A case study. Water 2014, 6, 2993-3011. [CrossRef]

11. Liu, X.; Xue, H.; Hua, Z.; Yao, Q. Inverse calculation model for optimal design of rectangular sedimentation tanks. J. Environ. Eng. 2012, 139, 455-459. [CrossRef]

12. Tarpagkou, R.; Pantokratoras, A. CFD methodology for sedimentation tanks: The effect of secondary phase on fluid phase using DPM coupled calculations. Appl. Math. Model. 2013, 37, 3478-3494. [CrossRef]

13. Zhang, J.M.; Lee, H.P.; Khoo, B.C.; Peng, K.Q.; Zhong, L.; Kang, C.W. Shape effect on mixing and age distributions in service reservoirs. J. Am. Water Work. Assoc. 2014, 106, E481-E491. [CrossRef]

14. Ferrara, V.; Erpicum, S.; Archambeau, P.; Pirotton, M.; Dewals, B. Flow field in shallow reservoir with varying inlet and outlet position. J. Hydraul. Res. 2018, 56, 689-696. [CrossRef]

15. Dufresne, M.; Dewals, B.; Erpicum, S.; Archambeau, P.; Pirotton, M. Numerical investigation of flow patterns in rectangular shallow reservoirs. Eng. Appl. Comput. Fluid Mech. 2011, 5, 247-258. [CrossRef]

16. Camnasio, E.; Orsi, E.; Schleiss, A.J. Experimental study of velocity fields in rectangular shallow reservoirs. J. Hydraul. Res. 2011, 49, 352-358. [CrossRef]

17. Wu, W. CCHE2D Sediment Transport Model (Version 2.1); Technical Rep. of National Center for Computational Hydroscience and Engineering NCCHE-TR-2001-03; University of Mississippi: Oxford, MS, USA, 2001. 
18. Shadloo, M.S.; Weiss, R.; Yildiz, M.; Dalrymple, R.A. Numerical simulation of long wave runup for breaking and nonbreaking waves. Int. J. Offshore Polar Eng. 2015, 25, 1-7.

19. Kantoush, S.; Bollaert, E.; Schleiss, A. Influence of the width of a rectangular shallow reservoir on sedimentation behaviour and trap efficiency. In Proceedings of the 32nd Congress of IAHR, Special Session 06 (SS06-07-0), Venice, Italy, 1-6 July 2007.

20. Dewals, B.J.; Kantoush, S.A.; Erpicum, S.; Pirotton, M.; Schleiss, A.J. Experimental and numerical analysis of flow instabilities in rectangular shallow basins. Environ. Fluid Mech. 2008, 8, 31-54. [CrossRef]

21. Janssen, R.H. Efficiency of Sediment Settling Basins, in Advances in Water Resources and Hydraulic Engineering; Springer: Berlin, Germany, 2009; pp. 2025-2030.

22. Toniolo, H. Numerical simulation of sedimentation processes in reservoirs as a function of outlet location. Int. J. Sediment Res. 2009, 24, 339-351. [CrossRef]

23. Camnasio, E.; de Cesare, G.; Kantoush, S.A. Flow field and sediment deposition in a rectangular shallow reservoir with non symmetric inlet and outlet configuration. In Proceedings of the Seventh International Symposium on Ultrasonic Doppler Methods for Fluid Mechanics and Fluid Engineering, Gothenburg, Sweden, 7-9 April 2010.

24. Bouisfi, F.; Bouisfi, A.; Che, H.O.; Bouhali, M.E.; Chaoui, M. The effect of inlet and outlet position and sediments concentration on sedimentation tank efficiency. In Proceedings of the 2018 4th International Conference on Optimization and Applications (ICOA), Morocco, Morocco, 26-27 April 2018.

25. Majdzadeh, T.M.R.; Pirestani, M.R.; Alimohamadi, S. Investigating the effect of inlet and outlet location on flow field and sedimentation pattern of a rectangular settling basin Using CCHE2D. J. Water Sci. Res. 2013, 5, 55-63.

26. Westhoff, M.C.; Erpicum, S.; Archambeau, P.; Pirotton, M.; Dewals, B. Maximum energy dissipation to explain velocity fields in shallow reservoirs. J. Hydraul. Res. 2018, 56, 221-230. [CrossRef]

27. Torabi, M.A.; Shafieefar, M. An experimental investigation on the stability of foundation of composite vertical breakwaters. J. Mar. Sci. Appl. 2015, 14, 175-182. [CrossRef]

28. Hadjadj, A.; Ben-Nasr, O.; Shadloo, M.S.; Chaudhuri, A. Effect of wall temperature in supersonic turbulent boundary layers: A numerical study. Int. J. Heat Mass Transf. 2015, 81, 426-438. [CrossRef]

29. Germano, M.; Piomelli, U.; Moin, P.; Cabot, W.H. A dynamic subgrid-scale eddy viscosity model. Phys. Fluids A Fluid Dyn. 1991, 3, 1760-1765. [CrossRef]

30. Ben-Nasr, O.; Hadjadj, A.; Chaudhuri, A.; Shadloo, M.S. Assessment of subgrid-scale modeling for large-eddy simulation of a spatially-evolving compressible turbulent boundary layer. Comput. Fluids 2017, 151, 144-158. [CrossRef]

31. Shojaeizadeh, A.; Reza Safaei, M.; Abdullah AA, A.A.; Ghodsian, M.; Geza, M.; Ammar Abbassi, M. Bed roughness effects on characteristics of turbulent confined wall jets. Measurement 2018, 122, 325-338. [CrossRef]

32. Shadloo, M.; Hadjadj, A.; Chaudhuri, A.; Ben-Nasr, O. Large-eddy simulation of a spatially-evolving supersonic turbulent boundary layer at $M_{\infty}=2$. Eur. J. Mech. B Fluids 2018, 67, 185-197. [CrossRef]

33. Wong, M.; Parker, G. Reanalysis and correction of bed-load relation of Meyer-Peter and Müller using their own database. J. Hydraul. Eng. 2006, 132, 1159-1168. [CrossRef]

34. Sangsefidi, Y.; Mehraein, M.; Ghodsian, M. Experimental study on flow over in-reservoir arced labyrinth weirs. Flow Meas. Instrum. 2018, 59, 215-224. [CrossRef]

35. Kantoush, S.A. Experimental Study on the Influence of the Geometry of Shallow Reservoirs on Flow Patterns and Sedimentation by Suspended Sediments. Ph.D. Thesis, Laboratoire de Constructions Hydrauliques, Lausanne, Switzerland, 2008.

36. Holdich, R.; Butt, G. Experimental and numerical analysis of a sedimentation forming compressible compacts. Sep. Sci. Technol. 1997, 32, 2149-2171. [CrossRef]

(C) 2018 by the authors. Licensee MDPI, Basel, Switzerland. This article is an open access article distributed under the terms and conditions of the Creative Commons Attribution (CC BY) license (http://creativecommons.org/licenses/by/4.0/). 